University of Nebraska - Lincoln

DigitalCommons@University of Nebraska - Lincoln

Faculty Papers and Publications in Animal

Science

Animal Science Department

2008

\title{
A Proposed Role for VEGF Isoforms in Sex-Specific Vasculature Development in the Gonad
}

\author{
Rebecca Bott \\ University of Nebraska-Lincoln \\ Debra T. Clopton \\ University of Nebraska-Lincoln, dclopton1@unl.edu \\ Andrea S. Cupp \\ University of Nebraska-Lincoln, acupp2@unl.edu
}

Follow this and additional works at: https://digitalcommons.unl.edu/animalscifacpub

Part of the Animal Sciences Commons

Bott, Rebecca; Clopton, Debra T.; and Cupp, Andrea S., "A Proposed Role for VEGF Isoforms in Sex-Specific Vasculature Development in the Gonad" (2008). Faculty Papers and Publications in Animal Science. 453. https://digitalcommons.unl.edu/animalscifacpub/453

This Article is brought to you for free and open access by the Animal Science Department at DigitalCommons@University of Nebraska - Lincoln. It has been accepted for inclusion in Faculty Papers and Publications in Animal Science by an authorized administrator of DigitalCommons@University of Nebraska - Lincoln. 
Published in Reproduction in Domestic Animals 43, Supplement 2 (2008), pp. 310-316; doi 10.1111/j.1439-0531.2008.01179.x

Copyright ( 2008 R. C. Bott, D. T. Clopton, and A. S. Cupp; journal compilation copyright @ 2008 Blackwell Verlag http://www.blackwell-synergy.com/loi/rda/ Used by permission.

\title{
A Proposed Role for VEGF Isoforms in Sex-Specific Vasculature Development in the Gonad
}

\author{
Rebecca C. Bott, Debra T. Clopton, and Andrea S. Cupp \\ Animal Science Department, University of Nebraska-Lincoln, Lincoln, NE, USA \\ Corresponding author - A. S. Cupp, A224i Animal Science Department, 38th and Fair Street, \\ University of Nebraska-Lincoln, Lincoln, NE 68583-0908, USA; acupp2@unl.edu
}

\begin{abstract}
Many scientists have expended efforts to determine what regulates development of an indifferent gonad into either a testis or ovary. Expression of Sry and upregulation of Sox9 are factors that initiate formation of the testis-specific pathway to allow for both sex-specific vasculature and seminiferous cord formation. Migration of mesonephric precursors of peritubular myoid cells and endothelial cells into the differentiating testis is a critical step in formation of both of these structures. Furthermore, these events appear to be initiated downstream from Sry expression. Sertoli cell secretion of growth factors acts to attract these mesonephric cells. One hypothesis is that a growth factor specific for these cell linages act in concert to coordinate migration of both peritubular and endothelial cells. A second hypothesis is that several growth factors stimulate migration and differentiation of mesonephric "stemlike" cells to result in migration and differentiation into several different cell lineages. While the specific mechanism is unclear, several growth factors have been implicated in the initiation of mesonephric cell migration. This review will focus on the proposed mechanisms of a growth factor, Vascular Endothelial Growth Factor, and how different angiogenic and inhibitory isoforms from this single gene may aid in development of testis-specific vascular development.
\end{abstract}

\section{Introduction}

Why study gonadal differentiation and sex-specific vascular development?

Infertility affects 40-70 million couples; of those approximately $50 \%$ of the infertility problems are attributed to male-related factors which include: low sperm count, abnormal spermatogenesis, and reduced androgen production (Skakkebaek 2004). In the past 12 years, the incidence of male infertility cases has increased at an alarming rate resulting in the development of a new syndrome-testicular dysgenesis syndrome. The reasons for the increase in testicular abnormalities are not understood but may be a result of genetic or environmental disruption of cell differentiation during testis morphogenesis (Skakkebaek 2004). Formation of testicular cords, and sex-specific vasculature, are the two morphological hallmarks that distinguish a testis from an ovary. Testis development is initiated by Sertoli cell differentiation and expression of Sry, causing mesonephric cell migration into the differentiating testis to form seminiferous cords. Removal of the mesonephros or blockage of mesonephric cell migration prevents cord formation. Thus, the migration of mesonephric derived cells, which include pre-endothelial and pre-peritubular cells, are critical to testis development.
What is known about embryonic testis morphogenesis?

In the mouse, the Sry gene is expressed in embryos at 10.5 days post-coitus (dpc) and ceases after 12.5 dpc. Sry induces expression of genes which cause differentiation of the Sertoli cell lineage from precursor somatic cells in the coelomic epithelium (Figure 1) (Cupp and Skinner 2005). So even though Sry function is important, expression in the rodent is brief. The Sertoli cell is the first cell of the testis to differentiate (Magre and Jost 1991). After differentiation, Sertoli cells begin to proliferate and simultaneously move into the gonad proper, forming aggregates with primordial germ cells. Proliferation of Sertoli cells increases the size of the testis, and this proliferation appears to be solely dependent on the expression of Sry (Schmahl et al. 2000). Without differentiation and proliferation of the Sertoli cells, the indifferent gonad would not develop into a testis.

After Sertoli cell differentiation, testicular cords and sexspecific vasculature develop to establish adult testis morphology. In the mouse, these events occur during 11.5$12 \mathrm{dpc}$ and are complete by $12.5 \mathrm{dpc}$ while in the rat these events occur between embryonic day 13.5-14 (Martineau et al. 1997). Induction of cord formation is initiated by cell migration from the adjacent mesonephros into the developing testis to surround the primordial germ and Sertoli cell aggregates (Buehr et al. 1993; Merchant-Larios et al. 1993). Mesonephric cell migration is the result of Sry regulated expression of paracrine growth factors secreted by Sertoli cells (Martineau et al. 1997). Paracrine growth factors act as chemo-attractants inducing mesonephric cell migration and cord formation (Ricci et al. 1999; Cupp et al. 2000, 2002, 2003; Colvin et al. 2001). If mesonephric cell migration is blocked, or if the mesonephros is removed, no cords will form. The population of cells that migrate from the mesonephros is proposed to be pre-endothelial and/ or pre-peritubular cells (Buehr et al. 1993; Merchant-Larios et al. 1993). Therefore, in addition to surrounding the Sertoli-primordial germ cell aggregates to form testis cords, the migrating mesonephric cells may also initiate the formation of vasculature within the developing testis. Platelet-derived growth factor (Uzumcu et al. 2002a) and VEGF (Bott et al. 2006) have been demonstrated to be necessary for cord formation; however, only VEGF has been demonstrated to be critical for both vascular development and cord formation. 


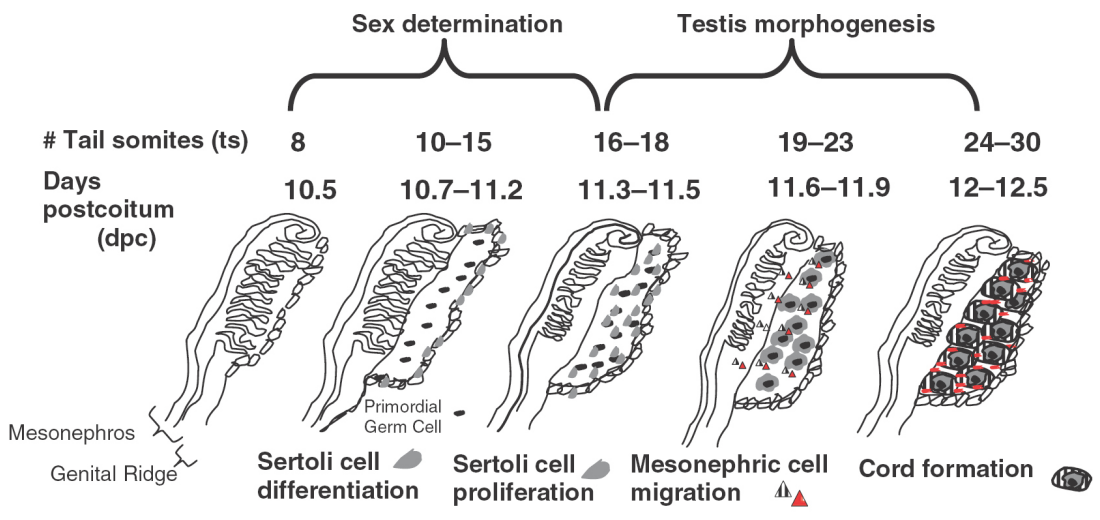

SRY mRNA
Figure 1. Sry-regulated events occurring during sex determination and testis morphogenesis using days post-coitum and tail somites as developmental markers (modified from Cupp and Skinner 2005)
What is known about formation of sex-specific vascular development?

Very little is known about what regulates sex specific vascular development in the gonads. Pre-endothelial cells in the indifferent gonad express markers for both veins (EphB4) and arteries (ephrin B2); however this changes as each gonad develops sex-specific structures. In the testis, endothelial cells migrate from the mesonephros and form vascular networks with arterial markers between cords and the coelomic vessel. The coelomic vessel is the major testicular artery that is formed when mesonephric endothelial cells migrate from the mesonephros into the testis and is unique to the testis. As endothelial cells differentiate a greater percentage develop into arteries and contribute to the coleomic vessel than those which contribute to veins within the testis. The development of arteries may be necessary to aid movement of testosterone to the developing male reproductive tract which allows for its maintenance and differentiation (Brennan et al. 2002). In contrast, the ovary develops similar amounts of arterial and venous networks from endothelial cells.

The origin of vasculature is different in the testis and ovary with vascular networks developing through angiogenesis (branching from existing vasculature in the mesonephros) in the testis and through vasculogenesis (de novo or neovascularization) in the ovary (Brennan et al. 2002). It is likely that the testis and ovary develop vascular patterns from different endothelial cell origins due to expression of sex-specific transcription factors. Furthermore, sex-specific transcription factors stimulate different growth factors to not only initate blood vessel formation but organ-specific support structures such as seminiferous cords or oogonial cysts.

Experiments using knockout mice demonstrate that disruption of vascular development also causes sex-reversal and abnormalities in germ cell development. Mice that are null for Wnt4 (Jeays-Ward et al. 2003) and Follistatin (Fst) (Yao et al. 2004) have sex-reversed XX gonads with ectopic expression of a coelomic vessel and vasculature surrounding seminiferous cord-like structures. The Wnt4 gene regulates expression of Fst so it is not surprising that mice null for both of these genes have the same phenotype. Follistatin is only expressed in the XX gonad and in general acts to inhibit activins. Therefore, there is potential for ac- tivins to be involved in formation of the coelomic vessel. In contrast Inhibin beta $\mathrm{b}$ (Inhbb) XY null mice do not form coelomic vessels $50 \%$ of the time. Thus, Inhbb null XY gonads are sometimes sex-reversed to $\mathrm{XX}$ vascular phenotypes. Activin A is composed of two inhibin beta a, Inhba, subunits while Activin B is composed of two Inhbb subunits. In the ovary, only Inhbb is expressed and not Inhba. Furthermore, expression of Inhbb is fourfold higher in the testis compared to the ovary at $12.5 \mathrm{dpc}$. Mating of Wnt4 and Inhbb null mice recapitulate the normal phenotype in $X Y$ gonads to form a coelomic vessel. Yet, matings between Inhbb and Fst null mice did not recapitulate the XY vascular phenotype, thus Wnt4 suppression of Inhbb appears to be independent of Fst inhibitory actions on activins (JeaysWard et al. 2003; Yao et al. 2006).

During normal testis development, Sry antagonizes expression of Wnt4 to suppress Fst and relieve inhibition of Inhbb (Figure 2). We can only speculate that Inhbb transcriptional regulation is due to expression of Sox-9, or other growth factors downstream of Sry expression. Inhbb stimulates endothelial cell migration and formation of a coelomic vessel. In XX gonads with no Wnt4 repression, Fst expression is increased and Inhbb expression is down regulated to prevent endothelial cell migration and formation of ovarian-specific vascular patterns (Yao et al. 2004).

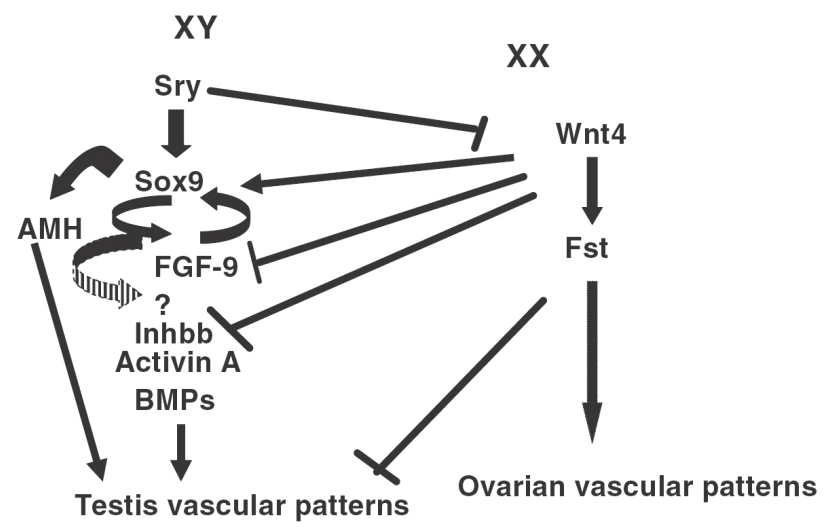

Figure 2. Genes demonstrated to be involved in sex-specific vascular patterns through development of null mice or treatment of indifferent gonads in organ culture 


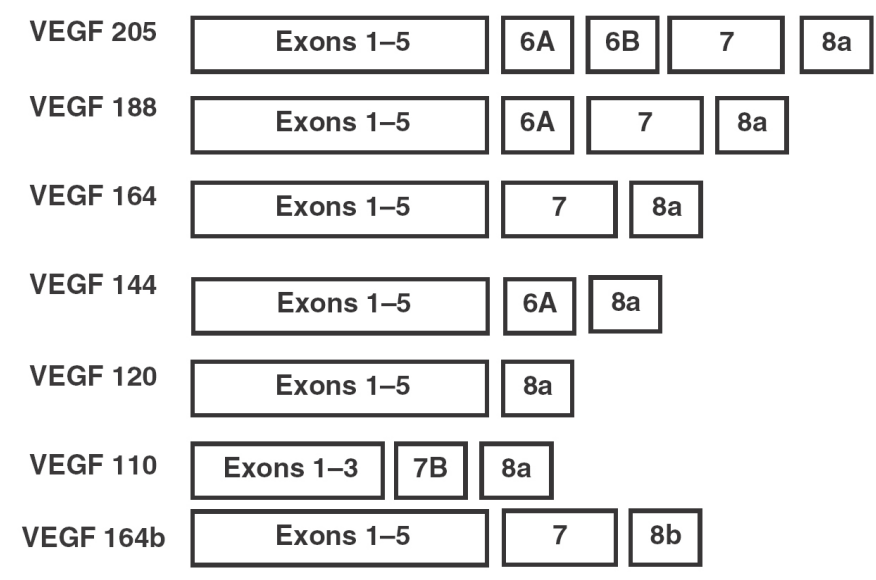

Figure 3. Exons in VEGF gene that compose each VEGF isoform.

In addition to the potential actions of Activin $\mathrm{B}, \mathrm{XX}$ gonads treated with bone morphogenic proteins (BMP), antimullerian hormone (AMH) and Activin A in vitro developed a sex-reversed phenotype with formation of an ectopic coelomic vessel; however, AMH deficient mice did not develop this same phenotype (Ross et al. 2003; Yao et al. 2004). Bone morphogenic protein, AMH, Activin A and Inhbb are members of the transforming growth factor-beta (TGF$\beta$ ) superfamily and directly regulate cell function through inhibition or activation of the SMAD signal transduction pathway. In the zebrafish, SMAD response elements in the promoter region of Vegfa gene also appear to regulate expression of different isoforms (He and Chen 2005). Thus, the Vegfa gene may be a downstream gene regulated by members of the TGF family to regulate sex-specific vasculature in the developing gonad (Figure 2).

What is known about the vascular endothelial growth factor family?

The VEGF family is composed of five ligands: VEGF (VEGFA), VEGF-B, VEGF-C, VEGF-D and placenta growth factor. VEGF (VEGF-A) is the best characterized and most potent VEGF molecule. VEGF works through both Fms-like tyrosine kinase 1 (FLT1) and Kinase domain region receptor (KDR), to elicit its effects on endothelial cell migration, differentiation, proliferation and survival and apoptosis. The primary receptor involved in neovascularization of organs with VEGF is KDR which contains a tyrosine kinase signal transduction domain (Waltenberger et al. 1994). There are conflicting reports about the role of FLT1 in regulation of VEGF's actions. In Flt1 knockouts, the mice die due to vasculature overgrowth suggesting that FLT1 acts as a decoy receptor to inhibit VEGF-dependent vascular development. Furthermore, FLT1 can also inhibit VEGF's actions by dimerizing with KDR to inhibit signal transduction. Thus, FLT1 appears to act as a negative regulator of VEGF's actions on endothelial cell migration, survival and proliferation (Ferrara 2000; Olsson et al. 2006).
Both mRNA and protein for VEGF and KDR are present during testis morphogenesis and are expressed in cells, like the Sertoli cell, that direct testis development. However, Flt1 is not expressed until after cord formation in the testis (Bott et al. 2006). The absence of FLT1 during mesonephric endothelial cell migration and establishment of vasculature in the testis may allow for endothelial cell migration through VEGF. In contrast, the ovary, which does not have mesonephric cell migration, expresses both Flt1 and Kdr during development (Pohlmann et al. 2004). Thus, VEGF angiogenic isoforms may be bound by FLT1 receptor in the ovary inhibiting the ability of mesonephric endothelial cells to be recruited into the developing ovary; thus providing a different endothelial cell origin for ovarian vasculature.

Vascular endothelial growth factor is transcribed from a single gene that has eight exons and is alternatively spliced into different isoforms each containing a different number of amino acids. The most common angiogenic isoforms are VEGF205, 188, 164, 144 and 120 (in humans the angiogenic isoforms are one amino acid longer; Figure 3). The predominant isoforms expressed in tissues are VEGF188, 164 and 120 (Veikkola and Alitalo 1999).

In 2002, an additional isoform, VEGF165b, was identified which contained part of the 3' UTR that is now determined to be exon $8 \mathrm{~b}$ (Figure 3). Furthermore, recent studies have demonstrated that the human VEGF165b isoform is anti-angiogenic in function and inhibits signal transduction through KDR (Bates et al. 2002; Woolard et al. 2004). Thus, this isoform is inhibitory to the actions of VEGF. Recently several other inhibitory isoforms have been identified in the human and we have cloned several in both the rat and bovine (VEGF165b accession number EU040284; VEGF189b accession number EU040285). Therefore, it appears that for every angiogenic isoform there is a sister inhibitory isoform that is formed when exon 8a is replaced with exon $8 \mathrm{~b}$. (In rodents and cattle the sister inhibitory isoform is one amino acid longer.) The primary functions of angiogenic VEGF isoforms are to induce endothelial cell migration, survival, proliferation and differentiation to initiate angiogenesis within developing organs and tumors. The inhibitory VEGF isoforms appear to modulate these functions.

In addition to the multiple VEGF isoforms, two co-receptors, neuropilin1 (NRP1) and neuropilin2 (NRP2), that bind to specific VEGF isoforms (i.e. VEGF164, VEGF188) have been identified. The predominant function of NRP1 appears to be stabilization of VEGF164 binding to KDR which augments signal transduction. The two co-receptors can also stabilize binding of VEGF isoforms to FLT1. In fact, FLT1 may regulate VEGF actions by tying up NRP bound isoforms. While both NRP co-receptors can bind to FLT1 it appears that only NRP1 can stabilize signal transduction through KDR. Interestingly, KDR, but not FLT1 is expressed during seminiferous cord formation (Bott et al. 2006) thus the ability of NRP1 to enhance signal transduction upon binding of VEGF isoforms to KDR may be critical during testis differentiation. 


\section{What Signal Transduction Pathways Does VEGF Activate Through KDR and Which Are Critical for Testis Cord Formation?}

Vascular endothelial growth factor induces the activation of several signal transduction pathways upon binding to KDR. Of these pathways, Phospholipase C gamma activates protein kinase $C$ causing activation of Ras or Raf and ultimately MAPK and ERK phosphorylation. The result of ERK phosphorylation is endothelial cell proliferation (Shu et al. 2002). The PI3-kinase pathway has been demonstrated to affect migration and permeability through Rac and permeability and survival through Akt (Gerber et al. 1998). The p38MAPK and FAK pathways are also postulated to affect actin reorganization and focal adhesion turnover to influence migration (Goligorsky et al. 1999). Several of these VEGF signal transduction pathways may interact to initiate endothelial cell differentiation, migration, proliferation and survival. Inhibition of the MAPK pathway affects cord formation (Uzumcu et al. 2002b) in testis organ cultures; however, PI3-kinase inhibits both seminiferous cord formation (Uzumcu et al. 2002b; Bott et al. 2006) and vascular development (Bott et al. 2006). Thus, both of these sex-specific events, vascular development and cord formation may be regulated by multiple growth factors through a similar signal transduction pathway.

What specific roles do the VEGF isoforms have in endothelial cell migration?

Endothelial cell recruitment and chemoattraction requires several different VEGF isoforms to establish a VEGF concentration gradient. At least three of the angiogenic VEGF isoforms are associated with specific endothelial cell functions (Veikkola and Alitalo 1999). VEGF120, a highly diffusible isoform, recruits endothelial cells into tissue to initiate the development of vasculogenesis while VEGF164 can recruit endothelial cells and establish large blood vessels. VEGF188, due to its heparin binding domain, acts locally to induce branching of large blood vessels into smaller capillaries and the development of capillary beds (Grunstein et al. 2000) (Figure 3). Furthermore, these three isoforms are thought to establish a VEGF chemoattractant gradient to allow for endothelial cell migration. In the testis, VEGF120, 188 and 164 are present during seminiferous cord formation and can develop a viable chemoattractant gradient (Bott et al. 2006). In contrast, in the ovary only VEGF164 and 120 are present (Pohlmann et al. 2004). The absence of the larger VEGF isoforms to anchor the chemoattractant gradient inhibits endothelial cell migration and weakens the attraction to VEGF secreting cells (Ruhrberg 2003). Therefore, in the ovary a viable chemoattractant gradient may not be present contributing to the lack of mesonephric cell migration.

VEGF165b is anti-angiogenic and appears to inhibit the actions of VEGF164 and to a lesser extent other VEGF isoforms. The inhibitory isoform, VEGF165b is expressed in all tissues but is down-regulated in prostate tumors (Woolard et al. 2004), renal tumors (Bates et al. 2002) and in disorders of the eye such as macular degeneration (Perrin et al. 2005). The mechanism of differential VEGF isoform expression is not known but is likely related to transcriptional and/ or post-transcriptional regulation of the VEGF gene which results in different ratios of angiogenic to inhibitory VEGF isoforms expressed.

One role of the inhibitory VEGF isoforms may be to inhibit the chemoattractant gradient and inhibit endothelial cell migration (Bates et al. 2002; Woolard et al. 2004). Our laboratory has subcloned and sequenced the rat VEGF165b and determined that there is a sex-specific expression of VEGF165b (fourfold higher in ovary than testis; unpublished data) during the time endothelial cell migration occurs. Therefore, the VEGF165b isoform may be expressed in the ovary to prevent establishment of a chemoattractant gradient and migration of endothelial cells from the mesonephros into the developing ovary.

\section{How are specific VEGF isoform actions regulated?}

Neuropilin1, a VEGFA co-receptor, appears to modulate VEGFA signal transduction (Klagsbrun and Eichmann 2005). Neuropilins were first identified as receptors for axon guidance forming complexes with the plexinA subfamily to modulate semaphorin signals (Takahashi et al. 1998). However, recent studies have identified a role for neuropilins in VEGF-dependent angiogenic processes. Specifically, NRP1 knockout mice have vasculature, heart and neural defects and die at E10.5-12.5 suggesting that NRP1 is necessary for normal vascular development (Kawasaki et al. 1999). If NRP1 binds to semaphorin instead of VEGF then endothelial cell migration is inhibited (Miao et al. 1999). Likewise, if NRP1/VEGF complexes bind to FLT1 this also may inhibit endothelial cell migration and the development of vasculature.

The predominant function of NRP1 appears to be stabilization of VEGFA164 binding to KDR which augments signal transduction. The two co-receptors can also stabilize binding of angiogenic VEGFA isoforms to FLT1. Infact, FLT1 may regulate angiogenic VEGF actions by enticing NRP bound isoforms to bind to this decoy receptor. While both NRP co-receptors can bind to FLT1 it appears that only NRP1 can stabilize signal transduction through KDR.

Initially, VEGFA isoforms containing exon 7 or a heparin binding domain (also in exon 6) were thought to bind to NRP1. However, there have been recent studies that suggest NRPs (in addition to binding to VEGF164 and 188 that contain heparin binding domains) also bind to VEGFA120 (which does not have a heparin binding domain). Although they bind VEGFA120, the interaction does not allow for the bridging of the two receptors (NRP1 and KDR) that occur with VEGF164 or 188. Therefore, the interaction with VEGF120 does not appear to stabilize and amplify signal transduction which occurs with VEGF164 (Pan et al. 2007).

Exon 8 a also appears to be important in binding of NRPs to VEGF angiogenic isoforms (Jia et al. 2006). It has been demonstrated that inhibitory VEGF isoforms such as $165 \mathrm{~b}$ cannot bind NRPs since exon $8 \mathrm{~b}$ replaces $8 \mathrm{a}$. Therefore, 
NRPs can convey angiogenic vs inhibitory isoform specificity to cells and if NRPs are eliminated from cells then the actions of angiogenic isoforms may be impaired.

\section{What regulates VEGF gene expression?}

Hypoxia (Schweda et al. 2000), oestradiol (Mueller et al. 2000), progesterone (Mueller et al. 2003), and factors signalling through the SMAD signal transduction pathway (He and Chen 2005) have all been implicated in increased or decreased expression of VEGF isoforms. Results from in vitro studies (Activin A/B, BMPs, AMH) (Yao et al. 2004) and null mice (Inhbb, Follistatin and Wnt4) (Yao et al. 2004, 2006) suggest that TGF- $\beta$ family members or proteins that inhibit their actions are involved in modulation of vascular development in the developing gonad. Interestingly, in the zebrafish SMAD response elements regulate VEGF gene expression (He and Chen 2005). Deletion of either SMAD1 or SMAD5 response elements on the zebrafish VEGF promoter resulted in either inhibition or enhanced transcription of the VEGF gene (He and Chen 2005). Within the murine VEGF promoter there are multiple consensus sequences for SMAD response elements (AS Cupp, unpublished data). Therefore, it is highly possible that growth factors signalling through the SMAD signal transduction pathways alter the expression of VEGF and VEGF-signal transduction mediators or potentially affect post-translational modification of VEGF to allow for different ratios of angiogenic vs inhibitory isoforms to be expressed (Figure 2).

\section{What Mouse Models Can Be Used to Understand the Function of VEGF During Testis Morphogenesis?}

Null mutations of VEGF are embryonic lethal with even the loss of one allele resulting in embryonic death at E11 dpc (Carmeliet et al. 1996; Ferrara et al. 1996). Similarly, homozygous knockouts for either receptor, FLT1 or KDR, die on 9-10 dpc (Millauer et al. 1994; Hiratsuka et al. 1998). Thus, these ubiquitous knockout models prevent us from determining the role of VEGF in testis morphogenesis and/or vascular patterning of the gonad. Overexpression of VEGF is equally detrimental to fertility and embryonic viability (Miquerol et al. 2000; Huminiecki et al. 2001).

Many conditional mutants have been developed which knock out VEGF ubiquitously later in development (in the neonate; Gerber et al. 1999) or in specific tissues (i.e. nerves in skin (Mukouyama et al. 2005). In these studies VEGF was determined to be required for proliferation and survival of endothelial cells. The deletion of VEGF in newborn mice in every cell of the body resulted in smaller mice that did not survive to adulthood. However, if VEGF was knocked out later in the fully developed animal there was less of an effect on growth.

Overexpression of VEGF in transgenic mice results in infertility (Korpelainen et al. 1998). Furthermore, overexpression of human $165 \mathrm{~b}$ through the MMLV promoter results in disruption of mammary gland development, and death postnatally in offspring from over-expressing females due to malnutrition (Qiu et al. 2007). However, until a testisspecific knockout mouse is developed it is unclear how removal of Sertoli-cell secretion of VEGF will affect testis development and function. Thus, further experiments need to be conducted in vivo to demonstrate the role of VEGF on sex-specific vascular development, seminiferous cord formation and testis function.

\section{Conclusion}

Approximately 2 million couples seek treatment for infertility every year and less than half find successful treatments (Carlsen et al. 2005). Infertility problems in at least half of these couples are a result of male-related factors that are created by testicular dysgenesis. Many of the problems associated with testicular dysgenesis are proposed to involve a disruption in embryonic differentiation of cells within the indifferent gonad resulting in altered testicular development. Elucidating the factors involved in sex-specific vascular development will allow for a better understanding of how transcription factors coordinate regulation of growth factors to result in a testis-specific vascular system. Furthermore, delineating the interaction of VEGF angiogenic and inhibitory isoforms in sex-specific vascular development promises to be an interesting piece in the puzzle of gonadal development.

\section{Acknowledgement}

This research was funded by NIH grants R03HD41546-01 and R03HD045350-01.

\section{References}

Bates D, Cui T-G, Doughty J, Winkler M, Sugiono M, Shields J, Peat D, Gillatt D, Harper S., 2002: VEGF $_{165}$ b, an inhibitory splice variant of vascular endothelial growth factor, is down-regulated in renal cell carcinoma. Cancer Res 62, 4123-4131.

Bott RC, McFee RM, Clopton DT, Toombs C, Cupp AS, 2006: Vascular endothelial growth factor and kinase domain region receptor are involved in both seminiferous cord formation and vascular development during testis morphogenesis in the rat. Biol Reprod 75, 56-67.

Brennan J, Karl J, Capel B, 2002: Divergent vascular mechanisms downstream of Sry establish the arterial system in the XY gonad. Dev Biol 244, 418-428.

Buehr M, Gu S, McLaren A, 1993: Mesonephric contribution to testis differentiation in the fetal mouse. Development 117, 273-281.

Carlsen E, Swan SH, Petersen JH, Skakkebaek NE, 2005: Longitudinal changes in semen parameters in young Danish men from the Copenhagen area. Hum Reprod 20, 942-949.

Carmeliet P, Ferreira V, Breier G, Pollefeyt S, Kieckens L, Gertsenstein M, Fahrig M, Vandenhoeck A, Harpal K, Eberhardt C, Declercq C, Pawling J, Moons L, Collen D, Ri- 
sau W, Nagy A, 1996: Abnormal blood vessel development and lethality in embryos lacking a single VEGF allele. Nature 380, 435-439.

Colvin JS, Green RP, Schmahl J, Capel B, Ornitz DM, 2001: Male-to-female sex reversal in mice lacking fibroblast growth factor 9. Cell 104, 875-889.

Cupp A, Skinner M, 2005: Embryonic sertoli cell differentiation. in: Griswold M, Skinner M (eds), Sertoli Cell Biology, Vol. 1. Elsevier Academic Press, San Diego, pp. 43-70.

Cupp AS, Kim GH, Skinner MK, 2000: Expression and action of neurotropin-3 and nerve growth factor in embryonic and early postnatal rat testis development. Biol Reprod 63, 1617-1628.

Cupp AS, Tessarollo L, Skinner MK, 2002: Testis developmental phenotypes in neurotropin receptor trkA and trkC null mutations: role in formation of seminiferous cords and germ cell survival. Biol Reprod 66, 1838-1845.

Cupp AS, Uzumcu M, Skinner MK, 2003: Chemotactic role of neurotropin 3 in the embryonic testis that facilitates male sex determination. Biol Reprod 68, 2033-2037.

Ferrara N, 2000: VEGF: an update on biological and therapeutic aspects. Curr Opin Biotechnol 11, 617-624.

Ferrara N, Carver-Moore K, Chen H, Dowd M, Lu L, O'Shea KS, Powell-Braxton L, Hillan KJ, Moore MW, 1996: Heterozygous embryonic lethality induced by targeted inactivation of the VEGF gene. Nature 380, 439-442.

Gerber HP, McMurtrey A, Kowalski J, Yan M, Keyt BA, Dixit V, Ferrara N, 1998: Vascular endothelial growth factor regulates endothelial cell survival through the phosphatidylinositol 3'-kinase/Akt signal transduction pathway. Requirement for Flk-1/KDR activation. J Biol Chem 273, 30336-30343.

Gerber H.-P, Hilan K, Ryan A, Kowalski J, Keller G.A, Rangell L, Wright B, Radtke F, Aguet M, Ferrara N, 1999: VEGF is required for growth and survival in neonatal mice. Development 126, 1149-1159.

Goligorsky MS, Abedi H, Noiri E, Takhtajan A, Lense S, Romanov V, Zachary I, 1999: Nitric oxide modulation of focal adhesions in endothelial cells. Am J Physiol 276, C1271-C1281.

Grunstein J, Masbad JJ, Hickey R, Giordano F, Johnson RS, 2000: Isoforms of vascular endothelial growth factor act in a coordinate fashion to recruit and expand tumor vasculature. Mol Cell Biol 20, 7282-7291.

He C, Chen X, 2005: Transcription regulation of the vegf gene by the BMP/Smad pathway in the angioblast of zebrafish embryos. Biochem Biophys Res Commun 329, 324-330.

Hiratsuka S, Minowa O, Kuno J, Noda T, Shibuya M, 1998: Flt1 lacking the tyrosine kinase domain is sufficient for normal development and angiogenesis in mice. Proc Natl Acad Sci U S A 95, 9349-9354.

Huminiecki L, Chan H, Lui S, Poulsom R, Stamp G, Harris A, Bicknell R, 2001: Vascular endothelial growth factor transgenic mice exhibit reduced male fertility and placental rejection. Mol Human Reprod 7, 255-264.

Jeays-Ward K, Hoyle C, Brennan J, Dandonneau M, Alldus G, Capel B, Swain A, 2003: Endothelial and steroidogenic cell migration are regulated by WNT4 in the developing mammalian gonad. Development 130, 3663-3670.

Jia H, Bagherzadeh A, Hartzoulakis B, Jarvis A, Lohr M, Shaikh S, Aqil R, Cheng L, Tickner M, Esposito D, Harris R, Driscoll PC, Selwood DL, Zachary IC, 2006: Characterization of a bicyclic peptide neuropilin-1 (NP-1) antagonist (EG3287) reveals importance of vascular endothelial growth factor exon 8 for NP-1 binding and role of NP-1 in KDR signaling. J Biol Chem 281, 13493-13502.

Kawasaki T, Kitsukawa T, Bekku Y, Matsuda Y, Sanbo M, Yagi T, Fujisawa H, 1999: A requirement for neuropilin-1 in embryonic vessel formation. Development 126, 4895-4902.

Klagsbrun M, Eichmann A, 2005: A role for axon guidance receptors and ligands in blood vessel development and tumor angiogenesis. Cytokine Growth Factor Rev 16, 535-548.

Korpelainen E, Karkkainen M, Tenhunen A, Lakso M, Rauvala H, Vierula M, Parvinen M, Alitalo K, 1998: Overexpression of VEGF in testis and epididymis causes infertility in transgenic mice: evidence for nonendothelial targets for VEGF. J Cell Biol 143, 1705-1712.

Magre S, Jost A, 1991: Sertoli cells and testicular differentiation in the rat fetus. J Electron Microsc Tech 19, 172-188.

Martineau J, Nordqvist K, Tilmann C, Lovell-Badge R, Capel B, 1997: Male-specific cell migration into the developing gonad. Curr Biol 7, 958-968.

Merchant-Larios H, Moreno-Mendoza N, Buehr M, 1993: The role of the mesonephros in cell differentiation and morphogenesis of the mouse fetal testis. Int J Dev Biol 37, 407-415.

Miao HQ, Soker S, Feiner L, Alonso JL, Raper JA, Klagsbrun M, 1999: Neuropilin-1 mediates collapsin-1/semaphorin III inhibition of endothelial cell motility: functional competition of collapsin-1 and vascular endothelial growth factor165. J Cell Biol 146, 233-242.

Millauer B, Shauver L, Plate K, Risau W, Ullrich A, 1994: Glioblastoma growth inhibited in vivo by a dominant-negative Flk-1 mutant. Nature 367, 576-579.

Miquerol L, Langille BL, Nagy A, 2000: Embryonic development is disrupted by modest increases in vascular endothelial growth factor gene expression. Development 127, 3941-3946.

Mueller MD, Vigne JL, Minchenko A, Lebovic DI, Leitman DC, Taylor RN, 2000: Regulation of vascular endothelial growth factor (VEGF) gene transcription by estrogen receptors alpha and beta. Proc Natl Acad Sci U S A 97, 10972-10977.

Mueller MD, Vigne JL, Pritts EA, Chao V, Dreher E, Taylor RN, 2003: Progestins activate vascular endothelial growth factor gene transcription in endometrial adenocarcinoma cells. Fertil Steril 79, 386-392.

Mukouyama YS, Gerber HP, Ferrara N, Gu C, Anderson DJ, 2005: Peripheral nerve-derived VEGF promotes arterial differentiation via neuropilin 1-mediated positive feedback. Development 132, 941-952.

Olsson AK, Dimberg A, Kreuger J, Claesson-Welsh L, 2006: VEGF receptor signalling - in control of vascular function. Nat Rev 7, 359-371.

Pan Q, Chathery Y, Wu Y, Rathore N, Tong RK, Peale F, Bagri A, Tessier-Lavigne M, Koch AW, Watts R. J, 2007: Neuro- 
pilin-1 binds to VEGF121 and regulates endothelial cell migration and sprouting. J Biol Chem 282, 24049-24056.

Perrin RM, Konopatskaya O, Qiu Y, Harper S, Bates DO, Churchill AJ, 2005: Diabetic retinopathy is associated with a switch in splicing from anti- to pro-angiogenic isoforms of vascular endothelial growth factor. Diabetologia 48, 2422-2427.

Pohlmann R, Clopton D, McFee R, Rozell T, Cupp A, 2004: Inhibition of Vascular Endothelial Growth Factor (VEGF) Signaling blocks follicle progression in the perinatal rat ovary. J Anim Sci 82, 233.

Qiu YBH, Weeraperuma S, Wratting D, Murphy D, Neal CR, Bates DO, Harper SJ, 2008: Mammary alveolar development during lactation is inhibited by the endogenous antiangiogenic growth factor isoform, VEGF165b. FASEB J 22, 1104-1112.

Ricci G, Catizone A, Innocenzi A, Galdieri M, 1999: Hepatocyte growth factor (HGF) receptor expression and role of HGF during embryonic mouse testis development. Dev Biol 216, 340-347.

Ross AJ, Tilman C, Yao H, MacLaughlin D, Capel B, 2003: $\mathrm{AMH}$ induces mesonephric cell migration in $\mathrm{XX}$ gonads. Mol Cell Endocrinol 211, 1-7.

Ruhrberg C, 2003: Growing and shaping the vascular tree: multiple roles for VEGF. BioEssays 25, 1052-1060.

Schmahl J, Eicher EM, Washburn LL, Capel B, 2000: Sry induces cell proliferation in the mouse gonad. Development $127,65-73$.

Schweda F, Blumberg FC, Schweda A, Nabel C, Holmer SR, Riegger GA, Pfeifer M, Kramer BK, 2000: Effects of chronic hypoxia on renal PDGF-A, PDGF-B, and VEGF gene expression in rats. Nephron 86, 161-166.

Shu X, Wu W, Mosteller RD, Broek D, 2002: Sphingosine kinase mediates vascular endothelial growth factor-induced activation of ras and mitogen-activated protein kinases. Mol Cell Biol 22, 7758-7768.
Skakkebaek NE, 2004: Testicular dysgenesis syndrome: new epidemiological evidence. Int J Androl 27, 189-191.

Takahashi T, Nakamura F, Jin Z, Kalb RG, Strittmatter SM, 1998: Semaphorins A and E act as antagonists of neuropilin-1 and agonists of neuropilin-2 receptors. Nat Neurosci 1, 487-493.

Uzumcu M, Dirks KA, Skinner MK, 2002a: Inhibition of platelet-derived growth factor actions in the embryonic testis influences normal cord development and morphology. Biol Reprod 66, 745-753.

Uzumcu M, Westfall SD, Dirks KA, Skinner MK, 2002b: Embryonic testis cord formation and mesonephric cell migration requires the phosphotidylinositol 3-kinase signaling pathway. Biol Reprod 67, 1927-1935.

Veikkola T, Alitalo K, 1999: VEGF's receptors and angiogenesis. Semin Cancer Biol 9, 211-220.

Waltenberger J, Claesson-Welsh L, Siegbahn A, Shibuya M, Heldin CH, 1994: Different signal transduction properties of KDR and Flt1, two receptors for vascular endothelial growth factor. J Biol Chem 269, 26988-26995.

Woolard J, Wang W-Y, Bevan H, Qui Y, Morbidelli L, Pritchard-Jones R, Cui T-G, Sugiono M, Waine E, Perrin R, Foster R, Digby-Bell J, Shields J, Whittles C, Muchens R, Gillatt D, Ziche M, Harper S, Bates D, 2004: VEGF ${ }_{165}$ b, an inhibitory vascular endothelial growth factor splice variant: mechanism of action, in vivo effect on angiogenesis and endogenous protein expression. Cancer Res 64, 7822-7835.

Yao HH, Matzuk MM, Jorgez CJ, Menke DB, Page DC, Swain A, Capel B, 2004: Follistatin operates downstream of Wnt4 in mammalian ovary organogenesis. Dev Dyn 230, 210-215.

Yao HH, Aardema J, Holthusen K, 2006: Sexually dimorphic regulation of inhibin beta $B$ in establishing gonadal vasculature in mice. Biol Reprod 74, 978-983. 